\title{
Non-covalent functionalized SWNTs as delivery agents for novel Bodipy-based potential PDT sensitizers $\dagger$
}

\author{
Received (in Cambridge, UK) 29th April 2009, Accepted 29th June 2009 \\ First published as an Advance Article on the web 21st July 2009 \\ DOI: $10.1039 / \mathbf{b 9 0 8 4 8 5 a}$
}

Sundus Erbas, ${ }^{a}$ Asli Gorgulu, ${ }^{b}$ Merve Kocakusakogullari $^{c}$ and Engin U. Akkaya ${ }^{* a c}$

Pyrenyl-functionalized distyryl-Bodipy sensitizer attached non-covalently to SWNTs was shown to generate singlet oxygen when excited at $660 \mathrm{~nm}$ with a red LED array; this work emphasizes the potential of SWNT as a viable alternative carrier of bioactive agents, including photodynamic therapy sensitizers.

Photodynamic therapy is a non-invasive methodology for the treatment of malignant tumors ${ }^{1}$ and age related macular degeneration. ${ }^{2}$ More recently, a significant cardiovascular potential for PDT was also demonstrated. ${ }^{3}$ The treatment in general involves systemic administration of a photosensitizer. The sensitizer lingers longer in tumor tissues due to what is known as enhanced permeation and retention (EPR). Then, irradiation of the tumor tissues with preferably red light (due to its higher tissue permeability) excites the sensitizer, which should undergo an intersystem crossing before it excites dissolved ground state oxygen to generate highly reactive and (hence) cytotoxic singlet oxygen. While porphyrins are the most commonly used PDT sensitizers, there are many potential candidates for this role, most with impressive characteristics, such as strong absorption of red to near IR light, efficient generation of singlet oxygen, high chemical stability and availability in a pure, single isomeric state. Two classes of dyes recently added to the growing arsenal of potentially useful PDT sensitizers are Bodipy ${ }^{4}$ derivatives and perylenediimides. ${ }^{5}$ Bodipy derivatives are especially interesting ${ }^{6}$ as these chromophores are easily derivatized to suit many applications. ${ }^{7}$ Previously, it was shown that iodine or bromine substitution on the Bodipy nucleus enhanced intersystem crossing, ${ }^{8}$ and a few promising sensitizers for use in photodynamic therapy have been reported in the last few years. ${ }^{4 a, 8 a}$

An important issue with regard to photodynamic therapy agents is the delivery of these molecules into the organs/tumor tissues/tissues cells. There are many strategies for drug targeting, but a satisfactory multifunctional delivery agent is nevertheless needed.

Single- (SWNTs) or multiwalled carbon nanotubes (MWNTs) are one distinct possibility. Previously, it was shown that carbon nanotubes are internalized by mammalian

${ }^{a}$ UNAM-Institute of Materials Science and Nanotechnology,

Bilkent University, 06800 Ankara, Turkey

${ }^{b}$ Department of Chemistry Education, Faculty of Education, Eskisehir Osmangazi University, 26480 Eskisehir, Turkey

${ }^{c}$ Department of Chemistry, Bilkent University, 06800 Ankara,

Turkey.E-mail: eua@fen.bilkent.edu.tr; Fax: +90 312-266-4068;

Tel: +90 312-290-2450

$\dagger$ Electronic supplementary information (ESI) available: Complete experimental details, additional spectra. See DOI: 10.1039/b908485a

Scheme 1 The target molecule 1, designed for non-covalent attachment to SWNTs.

cells ${ }^{9}$ through endocytosis, ${ }^{10}$ however other mechanisms may also be operational. ${ }^{11}$ Furthermore, they are excreted from the body rapidly and solubilized carbon nanotubes seem to have no significant cytotoxicity. ${ }^{12}$ They can be chemically modified ${ }^{13}$ to carry active agents or targeting groups which could be linked covalently. However, non-covalent modification ${ }^{14}$ is even more promising, since it would be much easier to carry out the required modifications, and multiple functionalities are as easily placed as a single type of functionality through non-covalent associations with the CNTs. To that end, we chose to make use of very strong pyrene-carbon nanotube $\pi-\pi$ interactions reported a few years ago. ${ }^{15}$ Thus, our target molecule (Scheme 1) carries a solubilizing group ( $\left.\mathrm{PEG}_{2000}\right)$, red absorbing chromophore (distyryl-Bodipy), intersystem crossing promoter heavy atoms (iodines at 2 and 6 positions of the Bodipy core), and two pyrene substituents on the styryl branches of the chromophore for $\pi$-stacking interactions with the SWNTs. The synthesis (Scheme 2) starts with reaction of 1,8-dichlorooctane with 4-hydroxybenzaldehyde in acetonitrile. The conditions were adjusted such that mono-substitution product (3) is the major product. Nevertheless, careful chromatographic purification was required to separate the desired product and any excess reactant. Pyrenyl group was then attached by the reaction of $\mathrm{NaH}$ deprotonated 2-pyrenylmethanol with compound 3 in DMF. For the generation and introduction of the Bodipy chromophore, a "clickable"16 Bodipy was needed. 4-Hydroxybenzaldehyde was reacted with propargyl bromide to yield $\mathbf{5}$. Then, the Bodipy core was obtained by a typical Bodipy synthesis reaction sequence.

Heavy atoms were placed by iodination with $\mathrm{I}_{2}-\mathrm{HIO}_{3}$ on positions 2 and 6 of Bodipy. Then, the two fragments were brought together by a double Knoevenagel condensation 

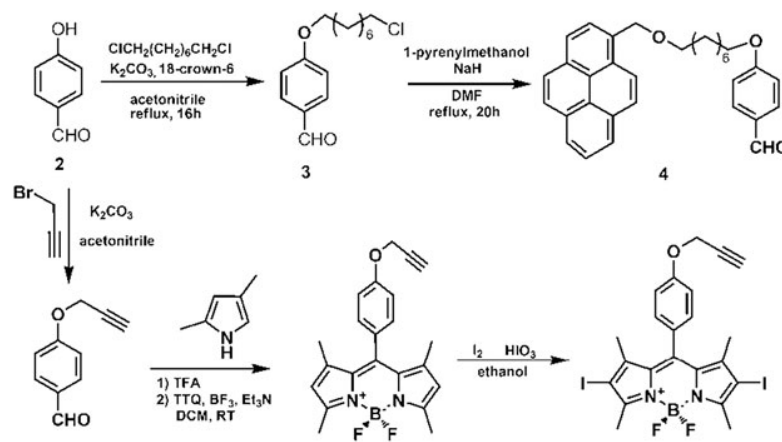

5
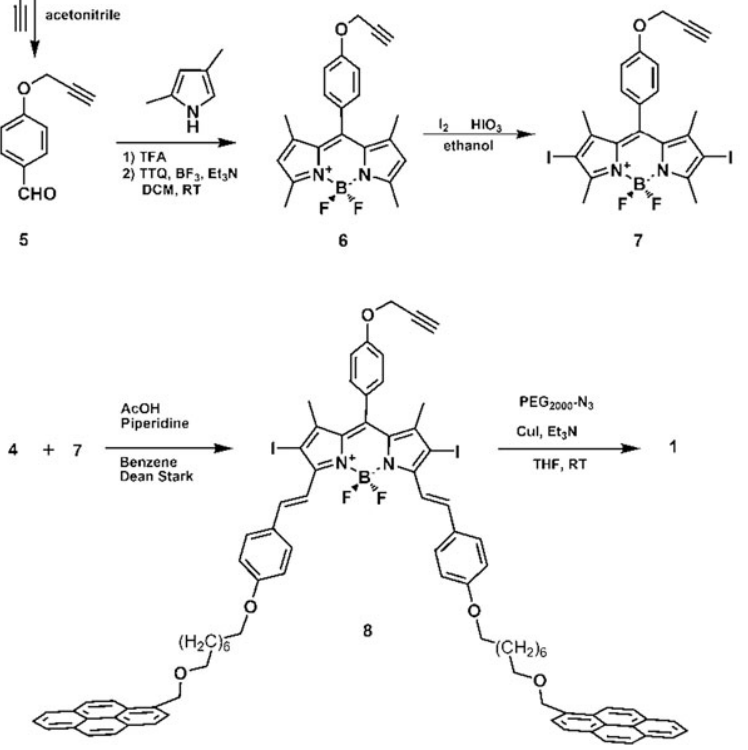

Scheme 2 Synthesis scheme for the target molecule 1.

reaction to yield distyryl modified ${ }^{17}$ compound $\mathbf{8}$. The final click reaction step was carried out between the azido-derivatized $\mathrm{PEG}_{2000}$ (synthesized according to the literature ${ }^{18}$ ) and the terminal alkyne 8. Silica gel column chromatography very cleanly separated unreacted azido-PEG from the intensely green colored product $\mathbf{1}$. Mass spectrometry clearly shows polymeric (due to PEG) peaks separated by an ethylene glycol derived unit (approximately $44 \mathrm{amu}$ ). In order to bring together the dye and carrier in the form of a non-covalent assembly, carbon nanotubes were treated in accordance with the literature for purification and debundling (breakdown of aggregate structures). ${ }^{19}$ Then the sensitizer carrying pyrene groups (1) was added at $0.5 \mathrm{mM}$ concentration dissolved in EtOH-PBS ( $1: 1, \mathrm{v} / \mathrm{v})$ mixture and sonicated for $1 \mathrm{~h}$ while being cooled externally. Centrifugation (11000 g) for $2 \mathrm{~h}$ followed by filtration through a $30 \mathrm{kDa}$ Millipore filter resulted in a clear and largely colorless solution, whereas functionalized SWNTs remained on the filter as a water soluble intense green colored substance. The absorbance and emission spectra, as expected, showed peaks of both Bodipy and pyrene units (supporting information $\dagger$ ). The absorbance spectra of neither pyrene nor Bodipy units were altered. This is in accordance with previous reports. ${ }^{20}$ Pyrene emission of the derivatized SWNTs was largely quenched in comparison to free sensitizer 1 at the same absorbance value at $400 \mathrm{~nm}$, again a clear indication of pyrene-SWNT interaction. ${ }^{20,21}$ Atomic force microscopy (Fig. 1) also confirmed the presence of separated and solubilized SWNTs. The rough tube surface indicates the presence of organic groups including relatively large PEG groups. The generation of singlet oxygen was monitored by the use of a selective singlet oxygen trap, diphenylisobenzofuran (Fig. 2). The non-covalent 1-SWNT
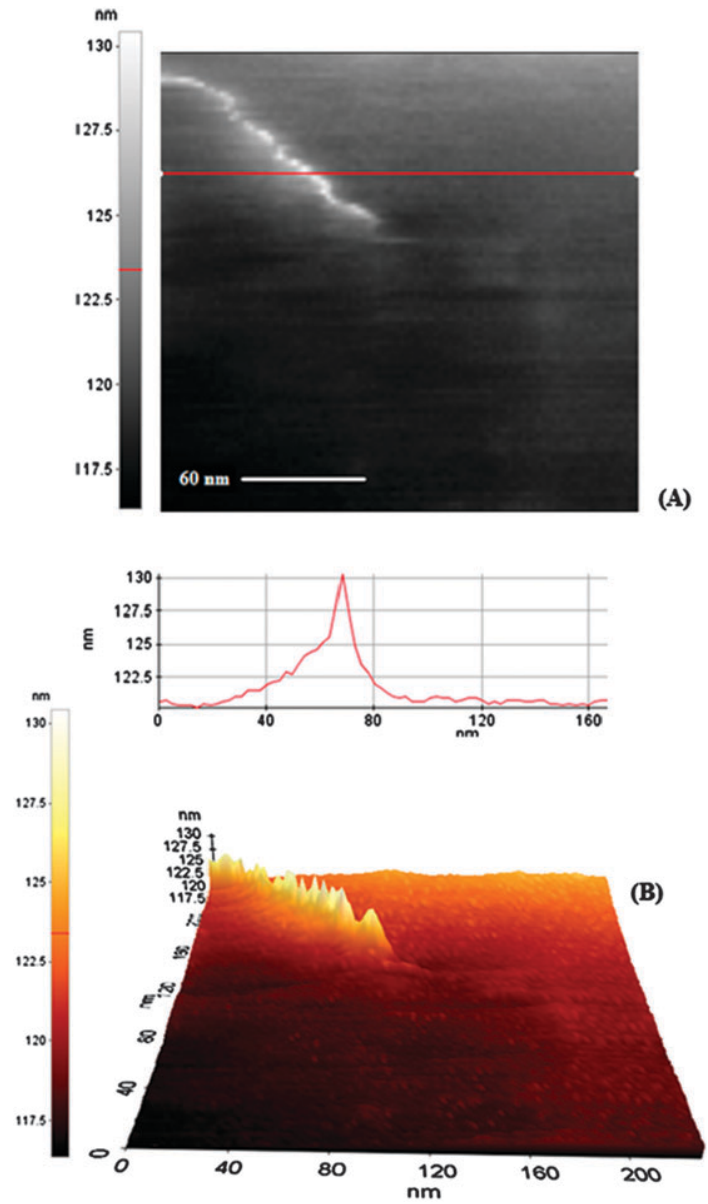

Fig. 1 (A) AFM image of compound 1-SWNT. (B) AFM 3D topographic view. PSIA XE-100E AFM and Multi75AI tip were used in non-contact mode with resonance frequency $75 \mathrm{kHz}$ and force constant $3.0 \mathrm{~N} \mathrm{~m}^{-1}$.

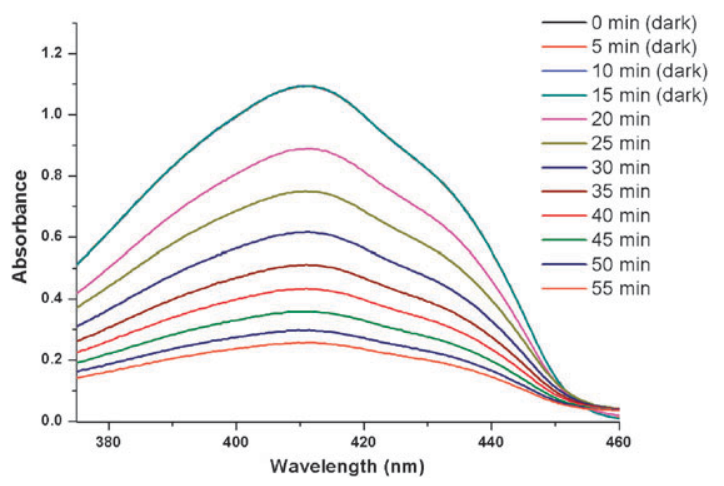

Fig. 2 Bleaching of 1,3-diphenylisobenzofuran $(50 \mu \mathrm{M})$ in isopropanol in the presence of SWNT-adsorbed compound $1(62 \mathrm{nM})$. The sample was kept in the dark for the first $15 \mathrm{~min}$ and then irradiated at $660 \mathrm{~nm}$ with a red LED array for $40 \mathrm{~min}$. Absorbance was measured at 5 min intervals. There is no decrease in absorbance in the dark, but there is a rapid degradation of the singlet oxygen trap when the irradiation of the sample is started.

derivative was dissolved in isopropyl alcohol, as the trap molecule is not soluble in water. In the dark, in the presence of 1-SWNT, no change in the absorbance of the singlet oxygen trap was observed for $15 \mathrm{~min}$. 


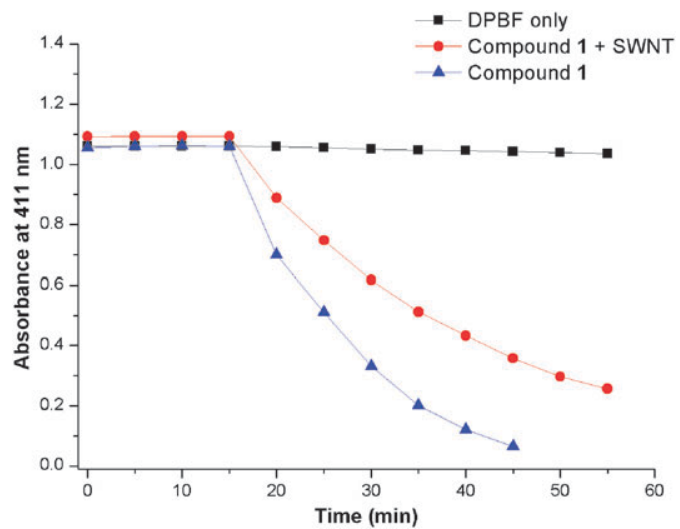

Fig. 3 Absorbance of DPBF in isopropanol at $411 \mathrm{~nm}$ without compound $\mathbf{1}$, in the presence of compound $\mathbf{1}$ only, and in the presence of compound 1 non-covalently attached to SWNT. Samples were kept in the dark for the first $15 \mathrm{~min}$ and then irradiated at $660 \mathrm{~nm}$ for $40 \mathrm{~min}$. Absorbance was measured at 5 min intervals. Black line: solution containing DPBF alone; red line: solution containing DPBF $(50 \mu \mathrm{M})$ and SWNT-adsorbed compound $\mathbf{1}(62 \mathrm{nM})$; blue line: solution containing DPBF $(50 \mu \mathrm{M})$ and compound 1 without SWNT (62 nM).

When the red LED array was turned on, rapid degradation started. In just $40 \mathrm{~min}$, the absorbance at $412 \mathrm{~nm}$ decreased to $1 / 5$ of the original value. Considering the low concentrations (62.0 $\mathrm{nM}$ and $50.0 \mu \mathrm{M}$ for the 1-SWNT and the trap compound, respectively) and low intensity irradiation, this is quite remarkable. In another experiment, we also showed that under the experimental conditions of the study, the trap molecule is not degraded by simple exposure to red light at $660 \mathrm{~nm}$ (Fig. 3). In conclusion, our work demonstrates that SWNTs can be useful delivery agents for photodynamic therapy. While a small decrease in the singlet oxygen generation efficiency is observed, that may be a small price to pay considering the additional benefit of non-covalent modifications through pyrenyl-SWNT interactions; as various targeting and signaling moieties can be brought together with equal ease on the SWNT carrier, resulting in a multifunctional PDT agent. Our work to that end is in progress.

The authors gratefully acknowledge partial support from the Turkish Academy of Sciences (TUBA). We also thank Dr Aykutlu Dana for his help and guidance in the acquisition of AFM images.

\section{Notes and references}

1 R. Bonnet, Chemical Aspects of Photodynamic Therapy, Gordon and Breach Science, Amsterdam, 2000.

2 R. Bonnet and G. Martinez, Tetrahedron, 2001, 57, 9513-9547.

3 (a) R. Waksman, P. E. McEwan, T. I. Moore, R. Pakala, F. D. Kolodgie, D. G. Hellinga, R. C. Seabron, S. J. Rychnovsky, J. Vasek, R. W. Scott and R. Virmani, J. Am. Coll. Cardiol., 2008, 52, 1024-1032; (b) S. G. Rockson, P. Kramer, M. Razavi, A. Szuba, S. Filardo, P. Fitzgerald, J. P. Cooke, S. Yousuf, A. R. DeVault, M. F. Renschler and D. C. Adelman, Circulation, 2000, 102, 2322-2324; (c) M. P. Jenkins, G. A. Buonaccorsi and M. Raphael, Br. J. Surg., 1999, 86, 1258-1263.

4 (a) S. Atilgan, Z. Ekmekci, A. L. Dogan, D. Guc and E. U. Akkaya, Chem. Commun., 2006, 4398-4400; (b) S. Ozlem and E. U. Akkaya, J. Am. Chem. Soc., 2009, 131, 48-49.
5 F. Yukruk, A. L. Dogan, H. Canpinar, D. Guc and E. U. Akkaya, Org. Lett., 2005, 7, 2885-2887.

6 (a) A. Loudet and K. Burgess, Chem. Rev., 2007, 107, 4891-4932; (b) G. Ulrich, R. Ziessel and A. Harriman, Angew. Chem., Int. Ed., 2008, 47, 1184-1201.

7 Selected recent examples: (a) S. Badre, V. Monnier, R. MealletRenault, C. Dumas-Verdes, E. Y. Schmidt, A. I. Mikhaleva, G. Laurent, G. Levi, A. Ibanez, B. A. Trofimov and R. B. Pansu, J. Photochem. Photobiol., A: Chem., 2006, 183, 238-246; (b) T. Rousseau, A. Cravino, T. Bura, G. Ulrich, R. Ziessel and J. Roncali, Chem. Commun., 2009, 1673-1675; (c) X. Qi, S. K. Kim, S. J. Han, L. Xu, A. Y. Jee, H. N. Kim, C. Lee, Y. Kim, M. Lee, S. J. Kim and J. Yoon, Tetrahedron Lett., 2008, 49, 261-264.

8 (a) A. Gorman, J. Killoran, C. O'Shea, T. Kenna, W. M. Gallagher and D. F. O'Shea, J. Am. Chem. Soc., 2004, 126, 10619-10631; (b) S. O. McDonnel, M. J. Hall, L. T. Allen, A. Byrne, W. M. Gallagher and D. F. O'Shea, J. Am. Chem. Soc., 2005 , 127, 16360-16361; (c) T. Yogo, Y. Urano, Y. Ishitsuka, F. Maniwa and T. Nagano, J. Am. Chem. Soc., 2005, 127, 12162-12163.

9 D. Pantarotto, J. P. Briant, M. Prato and A. Bianco, Chem. Commun., 2004, 16-17.

10 (a) N. W. S. Kam, T. C. Jessop, P. A. Wender and H. J. Dai, J. Am. Chem. Soc., 2004, 126, 6850-6851; (b) N. W. S. Kam, Z. Liu and H. Dai, Angew. Chem., Int. Ed., 2005, 44, 1-6.

11 K. Kostarelos, L. Lacerda, G. Pastorin, W. Wu, S. Wieckowski, J. Luangsivilay, S. Godefroy, D. Pantarotto, J. P. Briand, S. Muller, M. Prato and A. Bianco, Nat. Nanotech., 2007, 2, $108-113$.

12 (a) Z. Liu, C. Davis, W. Cai, L. He, X. Chen and H. Dai, Proc. Natl. Acad. Sci. U. S. A., 2008, 105, 1410-1415; (b) M. L. Schipper, N. Nakayama-Ratchford, C. R. Davis, N. W. S. Kam, P. Chu, Z. Liu, X. Sun, H. Dai and S. S. Gambhir, Nat. Nanotech., 2008, 3, 216-221.

13 (a) L. Qu, R. B. Martin, W. Huang, K. Fu, D. Zweifel, Y. Lin, Y. P. Su, C. E. Bunker, B. A. Harruff, J. R. Gord and L. F. Allard, J. Chem. Phys., 2002, 117, 8089-8094; (b) A. Hirsch, Angew. Chem., Int. Ed., 2002, 41, 1853-1859; (c) A. Hirsch and O. Vostrowski, Top. Curr. Chem., 2005, 245, 193-223; (d) H. Hu, Y. Ni, S. K. Mandal, V. Montana, B. Zhao, R. C. Haddon and P. Parpura, J. Phys. Chem. B, 2005, 109, 4285-4289; (e) R. Singh, D. Pantarotto, D. McCarthy, O. Chaloin, J. Hoebeke, C. D. Partidos, J. P. Briand, M. Prato, A. Biancho and A. Kostarelos, J. Am. Chem. Soc., 2005, 127, 4388-4396; (f) S. Dhar, Z. Liu, J. Thomale, H. Dai and S. J. Lippard, J. Am. Chem. Soc., 2008, 130, 11467-11476; $(g)$ J. Chen, S. Chen, X. Zhao, L. V. Kuznetsova, S. S. Wong and I. Ojima, J. Am. Chem. Soc., 2008, 130, 16778-16785.

14 (a) Z. Liu, M. Winters, M. Holodniy and H. Dai, Angew. Chem., Int. Ed., 2007, 46, 2023-2027; (b) N. Shao, S. Lu, E. Wickstrom and B. Panchapakesan, Nanotechnology, 2007, 18, 315101-315109; (c) Z. Zhu, Z. Tang, J. A. Phillips, R. Yang, H. Wang and W. Tan, J. Am. Chem. Soc., 2008, 130, 10856-10857; (d) B. Kang, D. Yu, S. Chang, D. Chen, Y. Dai and Y. Ding, Nanotechnology, 2008, 19, 375103-375110; (e) H. G. Sudibya, J. Ma, X. Dong, S. Ng, L. J. Li, X. W. Liu and P. Chen, Angew. Chem., Int. Ed., 2009, 48, 2723-2726.

15 R. J. Chen, Y. Zhang, D. Wang and H. Dai, J. Am. Chem. Soc., 2001, 123, 3838-3839.

16 W. T. Christian, C. Christensen and M. Meldal, J. Org. Chem., 2002, 67, 3057-3064.

17 (a) N. Saki, T. Dinc and E. U. Akkaya, Tetrahedron, 2006, 62, 2721-2725; (b) Z. Dost, S. Atilgan and E. U. Akkaya, Tetrahedron, 2006, 62, 8484-8488.

18 H. Zhao, B. Rubio and J. Xia, U.S. Pat., $7301003,2005$.

19 Z. Liu, W. Cai, L. He, N. Nakayama, K. Chen and X. Sun, Nat. Nanotech., 2007, 2, 47-52.

20 T. Ogoshi, Y. Takashima, H. Yamaguchi and A. Harada, J. Am. Chem. Soc., 2007, 129, 4878-4879.

21 F. D'Souza, R. Chitta, A. S. D. Sandanayaka, N. K. Subbaiyan, L. D'Souza, Y. Araki and O. Ito, J. Am. Chem. Soc., 2007, 129, 15865-15871. 